\title{
Mature forms of the major seed storage albumins in sunflower: a mass spectrometric approach
}

Bastian Franke ${ }^{1}$, Michelle L. Colgrave ${ }^{2}$, Joshua S. Mylne ${ }^{3}$, K. Johan Rosengren ${ }^{1 *}$

${ }^{1}$ The University of Queensland, School of Biomedical Sciences, Brisbane, QLD 4072, Australia

${ }^{2}$ CSIRO Agriculture, 306 Carmody Road, St Lucia, QLD 4067, Australia

${ }^{3}$ The University of Western Australia, School of Chemistry and Biochemistry \& ARC Centre of Excellence in Plant Energy Biology, 35 Stirling Highway, Crawley, Perth 6009, Australia

*Address correspondence to:

K. Johan Rosengren, The University of Queensland, School of Biomedical Sciences, Brisbane, QLD 4072, Australia. E-mail: j.rosengren@uq.edu.au; Phone: +61 733651403 


\begin{abstract}
:
Seed storage albumins are abundant, water-soluble proteins that are degraded to provide critical nutrients for the germinating seedling. It has been established that the sunflower albumins encoded by SEED STORAGE ALBUMIN 2 (SESA2), SESA20 and SESA3 are the major components of the albumin-rich fraction of the common sunflower Helianthus annuus. To determine the structure of sunflowers most important albumins we performed a detailed chromatographic and mass spectrometric characterization to assess what post-translational processing they receive prior to deposition in the protein storage vacuole. We found that SESA2 and SESA20 each encode two albumins. The first of the two SESA2 albumins (SESA2-1) exists as a monomer of 116 or 117 residues, differing by a threonine at the C-terminus. The second of the two SESA2 albumins (SESA2-2) is a monomer of 128 residues. SESA20 encodes the albumin SESA20-2, which is a 127residue monomer, whereas SESA20-1 was not abundant enough to be structurally described. SESA3, which has been partly characterized previously, was found in several forms with methylation of its asparagine residues. In contrast to other dicot albumins, which are generally matured into a heterodimer, all the dominant mature sunflower albumins SESA2, SESA20-2, SESA3 and its post-translationally modified analogue SESA3-a are monomeric.

Significance: Sunflower plants have been bred to thrive in various climate zones making them favored crops to meet the growing worldwide demand by humans for protein. The abundance of seed storage proteins makes them an important source of protein for animal and human nutrition. This study explores the structures of the dominant sunflower napin-type seed storage albumins to understand what structures evolution has favored in the most abundant proteins in sunflower seed.
\end{abstract}

Keywords: Helianthus annuus, seed storage albumin, napin, asparaginyl endopeptidase (AEP), post-translational processing 


\section{Introduction:}

Sunflower (Helianthus annuus) is native to North America [1] and was first cultivated by the American Indians as early as 3000 BC [2]. Its early uses by the American Indians were as a flour for cakes and bread or as a meal that was added to beans, squash and corn. Commercialization first occurred in Russia in the $18^{\text {th }}$ century [2] after introduction into Europe by Spanish explorers. The most well-known use as sunflower oil was first realized in 1716 when an English patent was granted for squeezing the oil from the seeds. Sunflower ranks among the top four crops grown for edible oil, including soybean, rapeseed and peanut. Sunflower oil is commonly used in food as a frying oil and to a lesser extent in cosmetics as an emollient (moisturizer). The seeds of sunflower are also consumed as a roasted or salted snack, dehulled with the kernels used as a confectionary nut, as feed for pets or silage for livestock $[3,4]$. Consumption of sunflower oil is also said to reduce cholesterol as well as confer antioxidant activity [5].

Seed storage proteins represent an important source of sulfur and nitrogen for the developing seedling after germination [6], and a valuable source of animal and human nutrition [7]. Sunflower seeds contain two main types of seed storage proteins, $11 \mathrm{~S}$ globulins and napin-type $2 \mathrm{~S}$ albumins. The water-soluble $2 \mathrm{~S}$ albumins account for about $60 \%$ of the total storage protein content in sunflower seeds, whereas the larger $11 \mathrm{~S}$ globulins comprise the remainder [8]. The nitrogen and sulfur content of sunflower seeds, reliant on the seed storage protein profile, changes according to the availability of soil nutrients [9].

Sunflower seed $2 \mathrm{~S}$ albumins are found in protein storage vacuoles and have a molecular mass between 10 and $20 \mathrm{kDa}$. Generally, 2S albumins are rich in the amino acids Asn, Asp, Gln, Glu and Cys and contain a well-conserved cysteine connectivity pattern (I-V, II-III, IV-VII and VI-VIII). They are synthesized as preproalbumins on the rough endoplasmic reticulum (ER) [10] where they are initially processed to proalbumins by removal of the $\mathrm{N}$-terminal ER signal domain. Formation of the conserved disulfide bonds occurs in the ER lumen due to its high oxidative redox potential, and is catalyzed by a protein disulfide isomerase [11,12]. As they migrate through the secretory pathway towards the vacuolar system, the $2 \mathrm{~S}$ albumins generally undergo further proteolytic processing with the final proteolytic cleavage occurring in the multivesicular bodies converting proalbumins to their final "mature" form in which they are found in the storage vacuole. In this context, mature is defined as the final protein product(s) after removal of the signal peptide, excision from the precursor protein and post-translational modification.

The proteolytic processing of proalbumins within the multivesicular bodies is mediated by asparaginyl endopeptidases (AEP) and an aspartic protease [12-14]. AEP removes the $\mathrm{N}$-terminal pro-region usually by cleavage after an Asn residue preceding the segment known as the small subunit (SSU). Generally AEP also cleaves at a second position after an Asn residue preceding the large subunit (LSU), creating a two-chain protein held together by disulfide bonds. An aspartic protease is thought to be responsible for trimming the sequence between the small and the large subunit [15]. However, not all proalbumins are processed to yield a heterodimeric albumin with small and large subunits. Kortt et al. (1990) isolated and purified the methionine-rich albumin SESA3 (also known as SFA8) from sunflower seeds and structural analysis by nuclear magnetic resonance (NMR) spectroscopy revealed that SESA3/SFA8 remains monomeric and is not cleaved into a small and a large subunit $[16,17]$.

The recent discovery of the highly unusual albumin precursors PawS1 and PawS2 has sparked new interest in albumins and their processing [18]. Sunflower PawS1 and PawS2 encode heterodimeric seed storage proteins, but each also encodes a small head-to-tail cyclized peptide. The sequences for the cyclic peptides reside between the N-terminal ER target signal domain and the region encoding the typical albumin [18]. Dual-product preproalbumins are not restricted to sunflower and a host of PawS-Derived Peptides appears to be similarly encoded within related members of the Asteraceae 
[19]. Intriguingly, most of the PawS-Derived Peptides do not appear to have protease inhibitor activity and their physiological significance is unknown. It appears that the trypsin inhibitory sequence of SFTI-1 evolved within the lineage that led to sunflower and might provide the seed with protection from insect predation [19].

We recently investigated the albumin profile of sunflower using genetic approaches including transcriptomics and showed that sunflower contains at least 26 genes for albumin, but mRNA support for only 15 of these was present in dry sunflower seeds [20]. Based on mRNA expression and reversed phase high performance liquid chromatography (RP-HPLC) fractionation, SESA2, SESA20-2 and SESA3/SFA8 were identified as the major components of the sunflower albumin profile [20], whereas PawS1 and PawS2 albumins were relatively minor components. In an analogous manner to that observed for one castor bean albumin precursor [21], the sunflower genes SESA2 and SESA20 appear to encode two distinct albumin proteins [20]. Although albumins from both SESA2 and SESA2O have been detected, little is known about their processing. To date, only sunflower PawS1, PawS2 and SESA3/SFA8 have been characterized in any detail at the protein level.

It has been shown that SESA3 forms highly stable solutions with oil/water mixtures, making it a promising food stabilizer with less allergenic responses than milk proteins. SESA3 is absorbed to the emulsion interface [22]. Burnett et al. (2002) showed that the sunflower albumins in the "Alb2 fraction" possessed emulsifying properties [23]. In this study, the fraction corresponding to the "Alb2 fraction" contains both SESA2 and SESA20, however further investigation is warranted to determine whether the individual albumins possess the ability to stabilize an emulsion.

Fluorescence studies of SESA3 in solution also indicated that a single tryptophan residue at position W76, which is located within the hyper-variable region, is re-oriented when it comes in contact with a water/oil interface [23]. Additionally, solution NMR studies revealed that W76 is surrounded by a hydrophobic patch consisting of four methionine residues. This flexibility and hydrophobicity may be responsible for a conformational change with the W76 side chain and some of its neighboring methionine side chains moving towards the oil phase [17].

To extend our knowledge of these proteins, we extracted albumins from sunflower seeds, purified and characterized the dominant albumins using a combination of chromatography and mass spectrometry approaches. The cumulative findings of this study provide new insights into the amino acid composition and post-translational processing events of seed storage albumins found in the common sunflower Helianthus annuus.

\section{Materials and Methods}

\section{Extraction of mature sunflower albumins}

Sunflower albumins were extracted by grinding $100 \mathrm{~g}$ of de-hulled sunflower seeds to a fine meal and then stirring in two tissue volumes of hexane for $5 \mathrm{~min}$ to remove oils. The slurry was filtered through a Whatman filter paper (No. 1) and the defatted meal was dried at room temperature for 1 $\mathrm{h}$, before resuspension in $200 \mathrm{~mL}$ of distilled water while stirring for $5 \mathrm{~min}$. The mixture was clarified by centrifugation $\left(9,056 \mathrm{x} \mathrm{g}, 10 \mathrm{~min}, 4^{\circ} \mathrm{C}\right)$ and the supernatant was dialyzed against water at $4^{\circ} \mathrm{C}$ overnight. The cloudy suspension was then centrifuged as above and the clear crude albumin-rich supernatant was retained and freeze-dried.

\section{FPLC and RP-HPLC isolation and purification of mature sunflower albumins}

To separate albumins from the crude sunflower protein mix, $300 \mathrm{mg}$ of crude albumin extract was resuspended in $3 \mathrm{~mL} 50 \mathrm{mM}$ sodium phosphate buffer $\mathrm{pH}$ 7, $150 \mathrm{mM}$ sodium chloride, $1 \mathrm{mM}$ DTT, and loaded onto a HiPrep 16/60 Sephacryl S-100 HR column (GE Healthcare Life Sciences) for size exclusion chromatography on an ÄKTA Start (GE Healthcare Life Sciences) using the external 
sample loop. Loading and elution flow rates were $1 \mathrm{~mL} / \mathrm{min}$ for size exclusion chromatography. The albumin-rich size exclusion fraction was desalted with buffer A using a PD-10 column (GE Healthcare Life Sciences) and lyophilized. The lyophilized albumin sample ( 10 mg) was then dissolved in buffer A and further separated by RP-HPLC on a Shimadzu Prominence (Rydalmere, Australia) using a semi-preparative Grace Vydac C18 column (250 mm x 10 mm, $10 \mu \mathrm{m}, 300 \AA$ ) and an analytical Phenomenex C18 Jupiter column (150 mm x $2 \mathrm{~mm}, 5 \mu \mathrm{m}, 300 \AA$ ) at a $1 \%$ gradient and a flow rate of $3 \mathrm{~mL} / \mathrm{min}$ and $0.3 \mathrm{~mL} / \mathrm{min}$ respectively. Buffer A consisted of $0.05 \%$ TFA and buffer B consisted of $0.05 \%$ TFA in $90 \%$ acetonitrile. Collected HPLC fractions were lyophilized and stored at $-20^{\circ} \mathrm{C}$. Several batches of seeds were extracted and analyzed during optimization of the extraction and purification protocols. In each instance, similar HPLC and LCMS profiles of the albumin fractions were observed.

\section{Monoisotopic and average mass determination}

A flake of each lyophilized albumin sample was dissolved in $100 \mu \mathrm{L}$ of water. A $25 \mu \mathrm{L}$ aliquot of this solution was mixed with $25 \mu \mathrm{L}$ of water and retained for analysis of the native form. Reduction and alkylation was achieved by first adding $5 \mu \mathrm{L}$ of $100 \mathrm{mM}$ dithiothreitol to the remaining $75 \mu \mathrm{L}$, with incubation for $30 \mathrm{~min}$ at $50^{\circ} \mathrm{C}$. Subsequently, $5 \mu \mathrm{L}$ of $250 \mathrm{mM}$ iodoacetamide was added and the samples incubated at room temperature in the dark for $30 \mathrm{~min}$. Prior to mass spectrometric analysis, $15 \mu \mathrm{L}$ of $0.5 \%$ formic acid was added.

Intact albumins (native or reduced and alkylated) were analyzed by LC-MS/MS on a Shimadzu Nexera uHPLC (Rydalmere, Australia) coupled to a TripleTOF ${ }^{\mathrm{TM}} 5600$ mass spectrometer (SCIEX, Toronto, Canada) equipped with a duo electrospray ion source. Each extract $(2 \mu \mathrm{L})$ was injected onto a $2.1 \mathrm{~mm}$ x $100 \mathrm{~mm}$ Zorbax C18 $1.8 \mu \mathrm{m}$ column (Agilent) at $400 \mu \mathrm{L} / \mathrm{min}$. Linear gradients of $2-40 \%$ solvent B over $10 \mathrm{~min}$ at $180 \mu \mathrm{L} /$ minute flow rate, followed by a steeper gradient from $40 \%$ to $80 \%$ solvent B over 3 min were used for protein elution. Solvent B was held at $80 \%$ for 3 min to wash the column before returning to $1 \%$ solvent $\mathrm{B}$ for re-equilibration prior to the next sample injection. Solvent A consisted of $0.1 \%$ formic acid (aq) and solvent B contained 90/10 acetonitrile/ $0.1 \%$ formic acid (aq). The ionspray voltage was set to $5300 \mathrm{~V}$, declustering potential (DP) $100 \mathrm{~V}$, curtain gas flow 35, nebuliser gas 1 (GS1) 45 , GS2 to 50, and the turbo heater to $450^{\circ} \mathrm{C}$. The mass spectrometer acquired $250 \mathrm{~ms}$ full scan TOF-MS data over the mass range 500-2200. The data were acquired and processed using Analyst TF 1.6 software (SCIEX). Theoretical masses of mature albumins were calculated using ExPasy PeptideMass [24].

\section{Sequencing of sunflower albumins}

Albumin samples (SESA3-a, SESA3-b and SESA3-c) were dissolved in $100 \mu \mathrm{L}$ of water. A $25 \mu \mathrm{L}$ aliquot of each albumin sample fraction was mixed with $25 \mu \mathrm{L}$ of $50 \mathrm{mM}$ ammonium bicarbonate containing $1 \mathrm{mM}$ calcium chloride ( $\mathrm{pH} \mathrm{8.0)}$ ). A volume of $5 \mu \mathrm{L} 100 \mathrm{mM}$ dithiothreitol was added and incubated for $30 \mathrm{~min}$ at $60^{\circ} \mathrm{C}$. To this, $5 \mu \mathrm{L}$ of $250 \mathrm{mM}$ iodoacetamide was added and incubated at room temperature in the dark for $60 \mathrm{~min}$. Then $0.5 \mu \mathrm{g}$ of trypsin (Sigma-Aldrich) was added to each aliquot and incubated at $37^{\circ} \mathrm{C}$ overnight. Prior to mass spectrometric analysis, $20 \mu \mathrm{L}$ of $1 \%$ formic acid was added.

The in-solution digested albumins were analyzed by LC-MS/MS on a Shimadzu Prominence Nano HPLC (Rydalmere, Australia) coupled to the 5600 TripleTOF $^{\mathrm{TM}}$ mass spectrometer (SCIEX) equipped with a nano electrospray ion source. Each extract $(10 \mu \mathrm{L})$ was injected onto a $50 \mathrm{~mm}$ x $300 \mu \mathrm{m}$ C18 trap column (Agilent Technologies, Australia) at $60 \mu \mathrm{L} / \mathrm{min}$. The samples were desalted on the trap column for 5 minutes using $0.1 \%$ formic acid (aq) at $60 \mu \mathrm{L} / \mathrm{min}$. The trap column was then placed in-line with the Zorbax 300SB-C18 HPLC column (150 mm x $100 \mu \mathrm{m}, 3.5 \mu \mathrm{m}$; Agilent Technologies, Australia) for peptide separation. A linear gradient of 2-40\% solvent B over $9 \mathrm{~min}$ at $500 \mathrm{~nL} /$ minute flow rate followed by a steeper gradient from $40-80 \%$ over $1 \mathrm{~min}$ and a hold at $80 \%$ for 1.5 min allowing peptide separation. The column was subsequently washed by increasing the solvent to $98 \%$ B over $0.5 \mathrm{~min}$ which was held at $98 \%$ for $1.5 \mathrm{~min}$ prior to a return to 
$2 \% \mathrm{~B}$ for re-equilibration (15 min) prior to the next sample injection. Solvent A consisted of $0.1 \%$ formic acid (aq) and solvent B contained 90/10 acetonitrile/ $0.1 \%$ formic acid (aq). The ionspray voltage was set to $2100 \mathrm{~V}$, declustering potential (DP) $100 \mathrm{~V}$, curtain gas flow 25, nebuliser gas 1 (GS1) 12 and interface heater at $160^{\circ} \mathrm{C}$. The mass spectrometer was set to acquire TOF-MS data over the mass range 300-1800 for 250 ms followed by 20 full scan product ion spectra over the mass range 80-1400 with a maximum accumulation time of $100 \mathrm{~ms}$ in Information Dependent Acquisition (IDA) mode. The 20 most intense ions observed in the TOF-MS scan exceeding a threshold of 200 counts and a charge state of +2 to +5 were set to trigger the acquisition of product ion MS/MS spectra. The data were acquired and processed using Analyst TF 1.6 software (SCIEX).

ProteinPilot ${ }^{\mathrm{TM}}$ software 4.0.0.0 (SCIEX) with the paragon algorithm [25] was used as the MS/MS ion search engine for the identification of albumin proteins. MS/MS data were searched against a custom-built database or a Uniprot database (version 2015/07; Helianthus; 2,930 proteins searched). Specifically, the search parameter settings were cysteine modification with iodoacetamide and trypsin as the digestion enzyme.

\section{Results}

\section{Isolation and purification of mature sunflower albumins}

To determine the existing variants of the main seed storage albumins present in sunflower seeds a proteomic approach for protein extraction, isolation and characterization was established. This involved $100 \mathrm{~g}$ of sunflower seeds being ground and defatted before extraction with water. The aqueous extract was separated by size exclusion chromatography using FPLC. From $100 \mathrm{~g}$ of sunflower seeds $\sim 140 \mathrm{mg}$ of dried albumin-rich fraction was recovered, representing a yield of $0.14 \%$. We then performed an RP-HPLC separation and isolated and purified SESA2-1, SESA20-2, SESA2-2, SESA3 and its post-translational analogues SESA3-a, SESA3-b and SESA3-c (Figure 1). The semi-pure post-translational variants of SESA3 were digested with trypsin, analyzed by MS/MS on a 5600 TripleTOF $^{\mathrm{TM}}$ mass spectrometer and the resulting spectra searched against public and custom-built protein databases. Identified variants of SESA3 shown in the chromatogram in Figure 1 are the primary identifications generated by database searching employing the ProteinPilot ${ }^{\mathrm{TM}}$ software.

Table 1 summarizes the diversity of sunflower albumins found in the seeds of the common sunflower Helianthus annuus. The heterodimeric sunflower albumins PawS1 and PawS2 originate from precursors that also produce cyclic peptides. The sunflower albumin SESA3 is in contrast a monomeric single chain protein. SESA2 and SESA20 each potentially encode two mature albumins [20], and while SESA2-1, SESA2-2 and SESA20-2 were further studied here, SESA20-1 was not of sufficient abundance to be structurally characterized.

\section{Reduction and alkylation reveals that the major sunflower albumins are monomers}

Sunflower albumins contain eight cysteines forming four disulfide bonds creating a compact and structured protein fold. In the case of the heterodimeric albumins, two of the disulfide bonds (intermolecular) link the two chains together while the remaining two are intramolecular in nature. A key question given that both heterodimeric and monomeric albumins have been found in sunflower extracts was whether the dominant albumins of sunflower were heterodimers or monomers. To address this, the sunflower albumins SESA2-1, SESA2-2 and SESA20-2 were subjected to reduction and alkylation and analyzed in comparison to SESA3 and its analog SESA3a by 1D gel-electrophoresis. For dimeric albumins, reduction of the disulfide bonds would yield two separate protein chains, whereas monomeric albumins would remain as a single chain. SESA2-1, SESA2-2, SESA20-2, SESA3 and SESA3-a all presented as single bands under both non-reducing and reducing conditions consistent with their existence as single chain monomers (Figure 2). This finding was further verified by the LC-MS analysis of native SESA2-1, SESA2-2, SESA20-2 and 
reduced and alkylated SESA2-1, SESA2-2, SESA20-2, as described in the following sections.

\section{Determination of processing sites of mature sunflower albumins}

To determine the processing sites in their precursor proteins, monoisotopic and average masses of the mature sunflower albumins SESA2-1, SESA20-2, SESA2-2, SESA3 and its post-translationally modified analogues SESA3-a, SESA3-b and SESA3-c were determined by LC-MS examining the native forms, i.e. prior to chemical treatment. Interestingly from this analysis it was clear that the SESA2-1, SESA3-a and SESA3-b fractions were all inhomogeneous each comprising two highly similar protein isoforms (Table 2). The average masses of the mature sunflower albumins SESA2-1, SESA20-2, SESA2-2 following reduction and alkylation were also determined by LC-MS. In the case of monomeric proteins, reduction would be expected to lead to an increase in mass as a result of cleavage of the disulfide bonds ( $2 \mathrm{Da}$ increase per bond) while treatment with iodoacetamide results in a further mass increase of 57 Da resulting from carbamidomethylation (forming a CysCam). If the albumins existed as heterodimers, the mass of the intact protein would be 18 Da more than a monomer owing to the presence of four termini (two termini per chain. Moreover, reduction would result in separation of the two chains (subunits). Comparing the experimentally obtained masses with the theoretical masses (for monomeric single-chain species) confirmed that the mature sunflower albumins SESA2-1, SESA2-2 and SESA20-2 are in fact monomeric, as is the case for SESA3 (Table 2).

SESA2 and SESA20 are both members of a multi-gene family and encode sunflower precursor proteins that comprise two distinct albumin sequences. The presence of a linker peptide between the two albumin domains of both SESA2 and SESA20 suggests that proteases separate and trim the exposed tails of the two albumins. To elucidate the sites that are subject to enzymatic cleavage we analyzed the mature albumins derived from SESA2 and SESA20.

\section{SESA2}

SESA2 encodes a 285 amino acid preproalbumin comprising an ER-signal domain, a pro-domain and two mature albumin domains connected by a linker peptide. Processing results in two mature albumins, SESA2-1 and SESA2-2, which are both monomeric.

The fraction containing SESA2-1 was purified to $29 \%$ based on analytical HPLC (Supplementary Figure 1A) and LC-MS indicated that the average mass of the two isoforms were 13,616 Da (Figure 3B, 3C) and 13,717 Da (Figure 3E, 3F). Despite the apparent high purity by HPLC, SESA2-1 was found to be a mixture of two isoforms, 116 and 117 amino acids in length. The mass difference of $101 \mathrm{Da}$ corresponds to an additional threonine at the C-terminus of SESA2-1 isoform II. Analysis of the full SESA2 sequence with the knowledge that AEP is involved in processing identified Asn33 as the N-terminal cleavage site and confirmed that the SESA2-1 mature albumin sequence is SESA2[34-149] for isoform I and SESA2[34-150] for isoform II, beginning with a Pro and ending with a Thr residue (Figure 3A). Reduction and alkylation with iodoacetamide resulted in a mass shift to 14,081 Da (Figure 3D) and 14,182 Da (Figure 3G), which corresponds to the alkylation of eight Cys residues and indicates the presence of four intramolecular disulfide bonds.

The second albumin (SESA2-2), which emerges from the same SESA2 precursor was purified to $\sim 95 \%$ based on analytical HPLC (Supplementary Figure 1C) and LC-MS showed an average mass of 15,292 Da (Figure 4B, 4C). SESA2-2 encodes a 128 amino acid monomeric single chain albumin with an albumin sequence of SESA2[158-285], beginning with Ile158 and ending with Tyr285 (Figure 4A). Consistent with AEP processing SESA2-2 is preceded by the AEP cleavage site Asn157. Reduction and alkylation of SESA2-2 with iodoacetamide resulted in a mass shift to $15,757 \mathrm{Da}$, consistent with alkylation of eight Cys residues forming four disulfide bonds (Figure 3D). 


\section{SESA20}

Like SESA2, SESA20 is synthesized as a preproalbumin with an N-terminal ER-domain, a prodomain and two mature albumin domains, which are connected by a linker peptide. The second albumin domain of the 290 amino acid preproalbumin, SESA20-2, was purified to $29 \%$ purity by HPLC (Supplementary Figure 1B). LC-MS analysis showed that SESA20-2 is processed to yield a 127 amino acid long mature albumin (SESA20-2), which exists in a monomeric form in a similar manner to SESA3 and SESA2. Comparison to the full SESA20 sequence identifies its mature albumin sequence as SESA20[164-290] starting with an Ile164 and ending with Tyr290 (Figure 5A). The N-terminal residue is preceded by the AEP cleavage site Asn163. LC-MS indicated an average mass of 15,064 Da (Figure 5B, 5C). Reduction and alkylation with iodoacetamide resulted in a mass shift to $15,530 \mathrm{Da}$ (Figure 5D), indicating the presence of four disulfide bonds. The first albumin SESA20-1 has previously been detected at the protein level [20] but was not abundant enough to be structurally characterized in this study.

\section{SESA3 and SESA3 variants}

The sunflower albumins SESA3-a (also known as SFA7) and SESA3 (also known as SFA8) were first reported in Kortt et al. (1990) and their amino acid composition was found to be identical and revealed a large content of sulfur-containing amino acids including $16 \mathrm{Met}$ and 8 Cys residues [16]. Using RP-HPLC and LC-MS/MS we separated two additional late-eluting albumin variants, SESA3-b and SESA3-c. Similar to SESA3-a, automated database searching yielded primary protein identifications for SESA3 (Table 3).

\section{SESA3-a}

Although the analytical RP-HPLC profile of SESA3-a shows a single peak, Kortt et al. (1990) first reported two albumins for the SESA3-a fraction (Figure 6A) [16]. In this study we also identified two isoforms by LC-MS with SESA3-a isoform I having an average mass of 12,216.2 Da and SESA3-a isoform II having an average mass of 12,230.7 Da, a difference of $14 \mathrm{Da}$ (Figure 6B, Table 2). No mass spectrometric evidence was found that the mass difference between either of the SESA3-a isoforms and SESA3, or the mass difference of 14 Da between the two isoforms of SESA3-a was due to a conservative amino acid substitution, e.g. Ser-Thr or Val-Ile/Leu, which are often the result of single nucleotide polymorphisms (SNPs). Instead the evidence suggests that methylation of Asn9 is likely to occur, which results in a mass shift of 14 Da between the two isoforms of SESA3-a. Isoform I shows no modification evident in the MS/MS spectrum (Figure 7A), whereas the MS/MS spectrum of isoform II shows a mass increase for the b9-ion (indicative of methylation at Asn9, Figure 7B). Relative to SESA3 isoform I of SESA3-a had an increased mass of $69 \mathrm{Da}$, we were however not able to identify the structural nature of this difference based on the MS/MS data.

\section{SESA3-b}

The sunflower albumin component SESA3-b has not been reported previously. Analytical HPLC gave rise to a single peak with a purity of $\sim 95 \%$ (Figure 6D), but interestingly again the LC-MS revealed a two-component system with two isomers with an average mass of 12,234.2 Da and 12,249.0 Da for SESA3-b isoform I and isoform II, respectively, a mass difference of 14 Da (Figure 6C). Based on the results of database searching, both isoforms of SESA3-b were considered as positive protein identifications again yielding SESA3 as the primary identification. This suggests that SESA3-b is also a post-translationally modified analogue of SESA3. Relative to SESA3, SESA3-b isoform I shows an increased mass of $87 \mathrm{Da}$, but the sites and nature of the modification(s) resulting in this difference, and the difference between the two isomers could not be confirmed for these components.

\section{SESA3-c}

The sunflower albumin component SESA3-c has also not been reported previously. Analytical HPLC gave rise to a single peak with a purity of $\sim 95 \%$ (Figure 6F). LC-MS revealed a single- 
component system with an average mass of 12,164.6 Da (Figure 6E), which represents an addition of 17 Da relative to SESA3. Based on the results of database searching, SESA3-c was considered a positive protein identification for SESA3, but the nature of the post-translational modification resulting in this mass increase could not be confirmed by the MS/MS analysis.

\section{Amino acid composition}

The amino acid compositions of the purified albumins SESA2, SESA20, PawS1, PawS2 and SESA3 are outlined in Table 4. All sunflower albumins possess eight conserved cysteine residues that form four disulfide bonds. In PawS1 and PawS2, two conserved inter-chain disulfide bonds connect the small and the large subunit (I-V and II-III) and two intra-chain disulfide bonds stabilize the large subunit (IV-VII and VI-VIII). Both isoforms of SESA2-1, which differ by a single threonine at the $\mathrm{C}$-terminus, show a high content of nitrogen containing groups i.e. glutamine (35\%) and arginine (8\%). SESA2-2 and SESA20-2 share an almost identical arrangement of glutamine, glutamic acid, arginine and asparagine, with a higher content of arginine and asparagine and lower content of glutamine than SESA2-1. PawS1 and Paws2 have a similar amino acid distribution rich in glutamine. SESA3 has been studied extensively and contains less nitrogen containing groups, but a high proportion of sulfur-containing methionine $(15.5 \%)$.

\section{Discussion}

Despite the importance of seed storage albumins for human and animal nutrition few investigations of the amino acid composition, sequences and structural characterization of $2 \mathrm{~S}$ albumins have been undertaken. In this study, three mature albumins and three analogues of a fourth albumin were isolated and purified by RP-HPLC and their molecular weights and amino acid sequences determined by mass spectrometric analysis. We show that the most abundant sunflower $2 \mathrm{~S}$ albumins are monomeric rather than the more common heterodimeric form. We also found some sunflower albumins that exist as a mixed population of two isoforms with subtle variations due to either different processing and/or chemical modifications.

\section{AEP-mediated post-translational processing}

Typically preproalbumins comprise an endoplasmic reticulum (ER) signal domain, a pro-domain and an albumin domain. Some sunflower preproalbumins deviate from this rule. PawS1 and PawS2 not only encode heterodimeric seed storage albumins, but also small cyclic peptides. SESA2 and SESA20 have two albumin domains that give rise to two mature albumins, each existing in a monomeric form. In contrast the monomeric albumin SESA3 originates from a classic preproalbumin gene with only a single albumin domain (Figure 8).

Analysis of mature albumins confirms that significant post-translational processing of preproalbumins occurs, and this processing takes place within the multivesicular bodies. The main player in the processing is the cysteine protease, AEP. The critical involvement of AEPs is particularly evident in the processing of PawS1. AEP cleaves PawS1 after the N-terminal pro region at the start of SFTI-1 and in the linker region at the start of the small and large subunit. AEP also cleaves after the Asp residue in SFTI-1, removing the "GLDN" tail and cyclizing SFTI-1 through a cleavage-coupled transpeptidation reaction $[18,28]$. An aspartic protease has been proposed to further mature the small and large subunit albumin by removing the linker peptide "LRMAVEN" $[14,15]$. Preproalbumins that only encode single chain proteins like SESA2-1, SESA2-2, SESA202 and SESA3 and its analogue SESA3-a are not cleaved into small and large subunits and remain as single chain albumins. In this instance AEP only removes the $\mathrm{N}$-terminal pro domain and cleaves after the residues preceding the second albumin domain to separate the two individual proteins.

Why are sunflower SESA2-1, SESA2-2 and SESA20-2 atypical monomeric albumins?

Heterodimeric $2 \mathrm{~S}$ albumins that are cleaved into a small and a large subunit by proteolytic 
processing can be found in a wide range of plant species e.g. oilseed rape [29], castor bean [30] [21], brazil nut [31], moringa [32] and sunflower [18]. As noted sunflower not only contains heterodimeric albumins like PawS1 and PawS2 [18], but also unusual monomeric albumins like SESA3 [16] and the SESA2-1, SESA2-2 and SESA20-2 described in this study. Sunflower seeds contain at least five AEPs of which AEP1 is highly expressed at the mRNA level [28]. To confirm its role in protein processing, AEP1 was produced in E. coli and an analysis of its activity showed it to have high specificity for Asn [28]. AEPs in general are thought to cleave preferably in vivo at Asn-Pro bonds [33]. Consistent with this, sunflower albumins that are cleaved into heteromers, like PawS1 and PawS2, possess an Asn preceding the Pro residue that marks the first residue of the large subunit. Notably, the precursor proteins for SESA2-1, SESA2-2 and SESA20-2 do not possess an Asn or Asp in the region where other sunflower proalbumins contain the AEP cleavage site(s) between the SSU and LSU. Although it is worth noting that AEP independent cleavage has been shown to occur for the At2S3 precursor in Arabidopsis thaliana, which lacks the Asn-Pro bond required by AEP [33] to produce a heterodimeric $2 \mathrm{~S}$ albumin. Our data suggest that in sunflower no AEP independent cleavage is occuring and the monomeric forms of these albumins is likely due to the lack of a preferred cleavage site. The mature sunflower albumin SESA3 does contain an AEPcleavage candidate Asn31 towards the end of the small subunit. SESA3 is the only sunflower albumin characterised structurally by NMR spectroscopy, which revealed that this potential AEPcleavage site is present near the end of a helix. The steric hinderance of the helical structure, and strong preference proteases have for their target residues to reside at the end of beta strands [34], would likely prevent sunflower AEPs (like AEP1) from cleaving SESA3 into a small and a large subunit.

\section{Isoforms with different processing site}

The albumin SESA2-1 was found to be a mixture of two isoforms, differing by a single threonine residue at the $\mathrm{C}$-terminus. Processing at chain termini during albumin maturation has previously been found to be associated with an involvement of an aspartic protease, which trims back the linker between the small and the large subunit after cleavage of AEP [15]. A similar processing of the linker between the two sunflower albumins that emerge from the same preproalbumin after cleavage by AEP would be required to produce the observed mature forms. The presence of two isoforms is likely due to the enzyme being able to process the Thr-Thr-Thr sequence to two different sites. A similar triple Thr motif is present in the linker region between the two albumin domains in SESA20, which suggests that SESA20-1 may also exist in different isoforms which together with its low abundance may contribute to the difficulty characterizing this protein by MS [20].

\section{Methylation as a post-translational modification}

Post-translational modifications of proteins increase the functional diversity and proteome complexity. These include e.g. post-translational methylation at oxygen, nitrogen and sulfur atoms. Methylation forming carboxyl esters on carboxyl groups are potentially reversible whereas the methylation of the sulfur of Cys and Met and the nitrogen at the $\mathrm{N}$-terminus or at the side chains of Arg, His, Lys, Asn and Gln are generally irreversible [35, 36].

Kortt et al. (1990) suggested that SESA3 and the two isoforms of SESA3-a share an identical amino acid composition characterized by a high content of the sulfur-rich amino acids, cysteine $(7.8 \%)$ and methionine $(15.5 \%)$ and that the two "components" of SFA7 had the same composition as the parental material [16]. The masses of SESA3-a isoform I and isoform II differ by 14 Da (Figure 6B), which corresponds to the mass shift of a covalently bound methyl group or an amino acid substitution from an Asn to a Lys/Gln. If an amino acid substitution would have had occurred at Asn9 to Lys9 it would have been highly likely that trypsin would have cleaved after Lys9. Our data did not support this theory, as there are no MS/MS spectra consistent with trypsin cleavage at a putative Lys9. The fragment DQVMSMAHK was not detected despite it having properties rendering it detectable by LC-MS/MS (size, composition). To change an asparagine to a glutamine 
at position 9, two single nucleotide changes would have had to occur within the one codon (Asn: AAT, AAC and Gln: CAA and CAG), which also appears highly unlikely. This suggests that methylation of Asn9 occurred in one of the isoforms of the SESA3 analogue SESA3-a, which resulted in the observed mass shift of $14 \mathrm{Da}$ (Figure 6B).

The two isoforms of SESA3-b like the SESA3-a isoforms differ in mass by $14 \mathrm{Da}$. No mass spectrometric evidence was found to unambiguously identify the site of modification resulting in the 14 Da shift between isoforms I and II of SESA3-b. However, given that methylation occurred at one of the isoforms of SESA3-a it would be logical to predict that that methylation would also be present in SESA3-b.

\section{Amino acid substitutions may explain mass differences in SESA3 analogues}

Intriguingly we were not able to confirm what modification(s) are responsible for the difference between SESA3 and SESA3-a, SESA3-b and SESA3-c. The observed mass differences of +69 Da, $+87 \mathrm{Da}$ and $+17 \mathrm{Da}$, respectively, do not match any obvious post-translational modifications. It is possible that they are the result of amino acid substitutions. A number of different isoforms with one and up to five amino acid substitutions have previously been reported for the most abundant $2 \mathrm{~S}$ albumin in yellow mustard seeds, Sin a 1 [37]. We were however not able to confirm whether this is also the case for SESA-3.

\section{Structural characteristics of sunflower albumins and relevance for food allergies}

Apart from the conserved Cys and the high amount of glutamine, glutamic acid and arginine, the amino acid composition and the sequence of sunflower albumins is quite diverse. Their overall structures are however expected to be more conserved, with all albumins for which structures have been solved comprising a conserved five-helical bundle structure creating a distinctive right-handed superhelix fold [12]. This compact fold is responsible for the high stability of the methionine-rich $2 \mathrm{~S}$ sunflower albumin SESA3 and the methionine-rich $2 \mathrm{~S}$ albumin Ber e 1 isolated from the Brazil nut Bertholletia excelsa to hydrolysis by simulated gastric fluid [38]. Alcocer et al. (2002) could also show that the recombinant $2 \mathrm{~S}$ albumin Ber e 1 was highly resistant against chemical denaturation (up to $4.5 \mathrm{M}$ guanidinium chloride) and high temperature (up to $95^{\circ} \mathrm{C}$ ) [39].

In terms of immune responses to albumins the $2 \mathrm{~S}$ albumins are considered to sensitize directly via the gastrointestinal tract where they are able to resist the harsh environment. Poor gastrointestinal protein digestibility is considered to be the major key factor of allergenicity, because intact proteins or large protein fragments are exposed to the gut immune system triggering an IgE-mediated food allergy [40]. Although sunflower seeds are extensively used in human consumption in the form of raw seeds, oil and spread, anaphylactic shock caused by sunflower seeds is rare. Only a few clinical studies are documented with SESA3 being the only known sunflower albumin showing IgE-binding activity [41-43]. Further studies into the allergenicity of albumins are required to understand the relationships between structural features, stability and immune responses. From a nutritional and allergen perspective it may be of advantage to identify high and low stability albumins to be able to select for particular albumin traits in breeding.

\section{Conclusion}

In summary this study provides insights into the amino acid composition and post-translational modifications of the major $2 \mathrm{~S}$ seed storage albumins for the common sunflower (Helianthus annuиs). Using chromatographic separation and mass spectrometry, we described the four major albumins SESA2-1, SESA2-2, SESA20-2 and the SESA3 isoform family. Like SESA3, all these major albumins remain as monomers and are not subject to cleavage into small and large subunits like most other albumins are, including the minor albumins from sunflower PawS1 and PawS2. A series of variants of the common albumins were identified and highlights the occurrence of both 
differences in processing of the primary sequence and post-translational modifications.

\section{Acknowledgments}

This work and B.F. were supported by Australian Research Council grant DP120103369 to K.J.R. and J.S.M. K.J.R. and J.S.M. were supported by Australian Research Council Future Fellowships FT130100890 and FT120100013 respectively. The authors thank the Compositae Genome Project website (http://cgpdb.ucdavis.edu/) supported by the USDA IFAFS Programme and NSF Plant Genome Programme for sunflower sequence data, Alun Jones and the Molecular and Cellular Proteomics Mass Spectrometry Facility (UQ) for access to the mass spectrometers used in this study.

\section{References}

[1] Heiser CB. The Origin and Development of the Cultivated Sunflower. Am Biol Teach. $1955 ; 17: 161-7$.

[2] Semelczi AK. Acclimatization and dissemination of the sunflower in Europe. Acta Ethnogr Acad Sci Hung. 1975;24:47-88.

[3] Lofgren JR. Sunflower for confectionery food, bird food, and pet food. Sunflower Technology and Production. Madison, WI: Agronomy Monograph; 1997. p. 747-64.

[4] Park CS, Marx GD, Wiesenborn D, Chang KCS, Hofman VL. Alternative Uses of Sunflower. Sunflower Technology and Production. Madison, WI: Agronomy Monograph; 1997. p. 765-807. [5] Bester D, Esterhuyse AJ, Truter EJ, van Rooyen J. Cardiovascular effects of edible oils: a comparison between four popular edible oils. Nutr Res Rev. 2010;23:334-48.

[6] Youle RJ, Huang AH. Albumin storage proteins in the protein bodies of castor bean. Plant Physiol. 1978;61:13-6.

[7] Young VR, Pellett PL. Plant proteins in relation to human protein and amino acid nutrition. Am J Clin Nutr. 1994;59:1203S-12S.

[8] Youle RJ, Huang AHC. Occurrence of Low Molecular Weight and High Cysteine Containing Albumin Storage Proteins in Oilseeds of Diverse Species. Am J Bot. 1981;68:44-8.

[9] Moss HJ, Wrigley CW, MacRitchie F, Randall PJ. Sulfur and Nitrogen Fertilizer Effects on Wheat. II* Influence on Grain Quality. Aust J Agric Res. 1981;32:213-26.

[10] Bollini R, Chrispeels MJ. The Rough Endoplasmic Reticulum Is the Site of Reserve-Protein Synthesis in Developing Phaseolus vulgaris Cotyledons. Planta. 1979;146:487-501.

[11] Onda Y, Nagamine A, Sakurai M, Kumamaru T, Ogawa M, Kawagoe Y. Distinct Roles of Protein Disulfide Isomerase and P5 Sulfhydryl Oxidoreductases in Multiple Pathways for Oxidation of Structurally Diverse Storage Proteins in Rice. Plant Cell. 2011;23:210-23.

[12] Mylne JS, Hara-Nishimura I, Rosengren KJ. Seed storage albumins: biosynthesis, trafficking and structures. Funct Plant Biol. 2014;41:671-7.

[13] Otegui MS, Herder R, Schulze J, Jung R, Staehelin LA. The Proteolytic Processing of Seed Storage Proteins in Arabidopsis Embryo Cells Starts in the Multivesicular Bodies. Plant Cell. 2006;18:2567-81.

[14] Gruis D, Selinger DA, Curran JM, Jung R. Redundant Proteolytic Mechanisms Process Seed Storage Proteins in the Absence of Seed-Type Members of the Vacuolar Processing Enzyme Family of Cysteine Proteases. Plant Cell. 2002;14:2863-82.

[15] Hiraiwa N, Kondo M, Nishimura M, Hara-Nishimura I. An aspartic endopeptidase is involved in the breakdown of propeptides of storage proteins in protein-storage vacuoles of plants. Eur $\mathrm{J}$ Biochem. 1997;246:133-41.

[16] Kortt AA, Caldwell JB. Low molecular weight albumins from sunflower seed: identification of a methionine-rich albumin. Phytochemistry. 1990;29:2805-10.

[17] Pantoja-Uceda D, Shewry PR, Bruix M, Tatham AS, Santoro J, Rico M. Solution Structure of 
a Methionine-Rich 2S Albumin from Sunflower Seeds: Relationship to Its Allergenic and Emulsifying Properties. Biochemistry. 2004;43:6976-86.

[18] Mylne JS, Colgrave ML, Daly NL, Chanson AH, Elliott AG, McCallum EJ, et al. Albumins and their processing machinery are hijacked for cyclic peptides in sunflower. Nat Chem Biol. 2011;7:257-9.

[19] Elliott AG, Delay C, Liu H, Phua Z, Rosengren KJ, Benfield AH, et al. Evolutionary Origins of a Bioactive Peptide Buried within Preproalbumin. Plant Cell. 2014;26:981-95.

[20] Jayasena AS, Franke B, Rosengren KJ, Mylne JS. A tripartite approach identifies the major sunflower albumins. Theor Appl Genet. 2016;129:613-17.

[21] Irwin SD, Keen JN, Findlay JBC, Lord JM. The Ricinus communis 2S albumin precursor: A single preproprotein may be processed into two different heterodimeric storage proteins. Mol Gen Genet. 1990;222:400-8.

[22] Guéguen J, Popineau Y, Anisimova IN, Fido RJ, Shewry PR, Tatham AS. Functionality of the 2S Albumin Seed Storage Proteins from Sunflower (Helianthus annuus L.). J Agric Food Chem. 1996;44:1184-9.

[23] Burnett GR, Rigby NM, Clare Mills EN, Belton PS, Fido RJ, Tatham AS, et al. Characterization of the Emulsification Properties of 2S Albumins from Sunflower Seed. J Colloid Interface Sci. 2002;247:177-85.

[24] Wilkins MR, Lindskog I, Gasteiger E, Bairoch A, Sanchez JC, Hochstrasser DF, et al. Detailed peptide characterization using PEPTIDEMASS-a World-Wide-Web-accessible tool.

Electrophoresis. 1997;18:403-8.

[25] Shilov IV, Seymour SL, Patel AA, Loboda A, Tang WH, Keating SP, et al. The Paragon Algorithm, a Next Generation Search Engine That Uses Sequence Temperature Values and Feature Probabilities to Identify Peptides from Tandem Mass Spectra. Mol Cell Proteomics. 2007;6:163855.

[26] Anisimova IN, Konarev AV, Gavrilova VA, Rozhkova VT, Fido RF, Tatham AS, et al. Polymorphism and inheritance of methionine-rich $2 \mathrm{~S}$ albumins in sunflower. Euphytica. 2003;129:99-107.

[27] Allen RD, Cohen EA, Vonder Haar RA, Adams CA, Ma DP, Nessler CL, et al. Sequence and expression of a gene encoding an albumin storage protein in sunflower. Mol Gen Genet.

1987;210:211-8.

[28] Bernath-Levin K, Nelson C, Elliott AG, Jayasena AS, Millar AH, Craik DJ, et al. Peptide Macrocyclization by a Bifunctional Endoprotease. Chem Biol. 2015;22:571-82.

[29] Ericson ML, Rödin J, Lenman M, Glimelius K, Josefsson LG, Rask L. Structure of the Rapeseed 1.7 S Storage Protein, Napin, and Its Precursor. J Biol Chem. 1986;261:14576-81. [30] Silva Jr JG, Machado OLT, Izumi C, Padovan JC, Chait BT, Mirza UA, et al. Amino Acid Sequence of a New 2S Albumin from Ricinus communis Which Is Part of a 29-kDa Precursor Protein. Arch Biochem Biophys. 1996;336:10-8.

[31] Ampe C, Van Damme J, de Castro LA, Sampaio MJ, Van Montagu M, Vandekerckhove J. The amino-acid sequence of the $2 \mathrm{~S}$ sulphur-rich proteins from seeds of Brazil nut (Bertholletia excelsa H.B.K.). Eur J Biochem. 1986;159:597-604.

[32] Ullah A, Mariutti RB, Masood R, Caruso IP, Gravatim Costa GH, Millena de Freita C, et al. Crystal structure of mature $2 \mathrm{~S}$ albumin from Moringa oleifera seeds. Biochem Biophys Res Commun. 2015;468:365-71.

[33] Shimada T, Yamada K, Kataoka M, Nakaune S, Koumoto Y, Kuroyanagi M, et al. Vacuolar Processing Enzymes Are Essential for Proper Processing of Seed Storage Proteins in Arabidopsis thaliana. J Biol Chem. 2003;278:32292-9.

[34] Madala PK, Tyndall JD, Nall T, Fairlie DP. Update 1 of: Proteases universally recognize beta strands in their active sites. Chem Rev. 2010;110:PR1-31.

[35] Klotz AV, Leary JA, Glazer AN. Post-translational Methylation of Asparaginyl Residues. Identification of $\beta$-71 $\gamma$ - $N$-Methylasparagine in Allophycocyanin. J Biol Chem. 1986;261:15891-4. [36] Clarke S. Protein methylation. Curr Opin Cell Biol. 1993;5:977-83. 
[37] Hummel M, Wigger T, Brockmeyer J. Characterization of Mustard 2S Albumin Allergens by Bottom-up, Middle-down, and Top-down Proteomics: A Consensus Set of Isoforms of Sin a 1. J Proteome Res. 2015;14:1547-56.

[38] Murtagh GJ, Archer DB, Dumoulin M, Ridout S, Matthews S, Arshad SH, et al. In vitro stability and immunoreactivity of the native and recombinant plant food $2 \mathrm{~S}$ albumins Ber e 1 and SFA-8. Clin Exp Allergy. 2003;33:1147-52.

[39] Alcocer MJC, Murtagh GJ, Bailey K, Dumoulin M, Sarabia Meseguer A, Parker MJ, et al. The Disulphide Mapping, Folding and Characterisation of Recombinant Ber e 1, an Allergenic Protein, and SFA8, Two Sulphur-rich 2 S Plant Albumins. J Mol Biol. 2002;324:165-75.

[40] Astwood JD, Leach JN, Fuchs RL. Stability of food allergens to digestion in vitro. Nat Biotechnol. 1996;14:1269-73.

[41] Noyes JH, Boyd GK, Settipane GA. Anaphylaxis to sunflower seed. J Allergy Clin Immunol. 1979;63:242-4.

[42] Kelly JD, Hlywka JJ, Hefle SL. Identification of Sunflower Seed IgE-Binding Proteins. Int Arch Allergy Immunol. 2000;121:19-24.

[43] Iwaya M, Murakami G, Kurose K, Matsuno M, Onoue Y, Takayanagi M, et al. A case of anaphylaxis caused by sunflower seed. Jap J Allerg. 1994;43:696-700. 
Table 1: Seed storage 2S albumins of the common sunflower (Helianthus annuus).

\begin{tabular}{lcccccc}
\hline & PawS1 & PawS2 & SESA3 & SESA2-1 & SESA2-2 & SESA20-2 \\
\hline $\begin{array}{l}\text { Residues (precursor): } \\
\text { Residues (mature }\end{array}$ & 151 & 137 & 141 & 285 & 285 & 290 \\
$\begin{array}{l}\text { albumin): } \\
\begin{array}{l}\text { Av. mature albumin } \\
\text { mass: }\end{array}\end{array}$ & 91 & 90 & 103 & $116 / 117$ & 128 & 127 \\
$\begin{array}{l}\text { Av. cyclic peptide } \\
\text { mass: }\end{array}$ & $10.5 \mathrm{kDa}$ & $10.4 \mathrm{kDa}$ & $12.2 \mathrm{kDa}$ & $13.6 \mathrm{kDa} / 13.7 \mathrm{kDa}$ & $15.3 \mathrm{kDa}$ & $15.1 \mathrm{kDa}$ \\
\begin{tabular}{l} 
Cyclic peptide name: \\
\hline
\end{tabular} & SFTI-1 & SFT-L1 & - & - & - & - \\
\hline
\end{tabular}


Table 2: Observed and calculated masses of sunflower albumins.

\begin{tabular}{|c|c|c|c|c|}
\hline & $\frac{\text { Observed }}{\underset{\text { Da }}{\text { average mass in }}}$ & $\begin{array}{l}\text { Calculated } \\
\underset{\text { Da }}{\text { average mass in }}\end{array}$ & $\begin{array}{c}\text { Observed } \\
\text { average mass } \\
\text { with Cys-Cam } \\
\text { modification in } \\
\text { Da }\end{array}$ & $\begin{array}{c}\text { Calculated } \\
\text { average mass } \\
\text { with Cys-Cam } \\
\text { modification in } \\
\text { Da } \\
\end{array}$ \\
\hline SESA2-1 isoform I & 13616.4 & 13616.3 & 14081 & 14080.7 \\
\hline SESA2-1 isoform II & 13717.5 & 13717.4 & 14182 & 14181.8 \\
\hline SESA2-2 & 15292.3 & 15292.2 & 15757 & 15756.6 \\
\hline SESA20-2 & 15065.4 & 15065.0 & 15530 & 15529.4 \\
\hline SESA3-a isoform I & 12216.2 & $---*$ & $---*$ & $---*$ \\
\hline SESA3-a isoform II & 12230.7 & $---*$ & $---*$ & $---*$ \\
\hline SESA3-b isoform I & 12234.2 & $---*$ & $---*$ & $---*$ \\
\hline SESA3-b isoform II & 12249.0 & $---*$ & $---*$ & $---*$ \\
\hline SESA3-c & 12164.6 & $---*$ & $---*$ & $---*$ \\
\hline
\end{tabular}


Table 3: Peptides identified after in-solution tryptic digestion of SESA3 isoforms.

\begin{tabular}{|c|c|c|c|c|}
\hline $\begin{array}{c}\text { Protein } \\
\text { analysed }\end{array}$ & $\begin{array}{c}\text { Protein } \\
\text { identified }\end{array}$ & $\begin{array}{c}\text { Sequence } \\
\text { coverage } \\
(\%)\end{array}$ & $\begin{array}{c}\text { Number } \\
\text { of } \\
\text { peptides } \\
>95 \%\end{array}$ & Identified peptide sequences \\
\hline SESA3-b & SESA3 & 49.7 & 4 & $\begin{array}{c}\text { CMCPAIMMMLNEPMWIR } \\
\text { LPIECNLMSQPCQM } \\
\text { MLNEPMWIR } \\
\text { MMLNEPMWIR }\end{array}$ \\
\hline SESA3-c & SESA3 & 64.5 & 1 & CMCPAIMMMLNEPMWIR \\
\hline SESA3-a & SESA3 & 67.4 & 7 & $\begin{array}{c}\text { GRTESGCYQQMEEAEMLNHCGMYLMK } \\
\text { TESGCYQQMEEAEMLNHCGMYLMK } \\
\text { QLCCMQLK } \\
\text { NLDEKCMCPAIMMMLNEPMWIR } \\
\text { CMCPAIMMMLNEPMWIR } \\
\text { MRDQVMSMAHNLPIECNLMSQPCQM } \\
\text { DQVMSMAHNLPIECNLMSQPCQM }\end{array}$ \\
\hline
\end{tabular}

*Peptides identified by ProteinPilot ${ }^{\mathrm{TM}}$ with a confidence $>95 \%$ from an LC-MS/MS analysis of purified HPLC fractions after in-solution digestion using trypsin. 
Table 4: Amino acid composition (number of residues) of isolated mature $2 S$ albumins from the seeds of the sunflower Helianthus annuus.

\begin{tabular}{cccccccc}
\hline Residue & $\begin{array}{c}\text { SESA2-1 } \\
\text { isoform I }\end{array}$ & $\begin{array}{c}\text { SESA2-1 } \\
\text { isoform II }\end{array}$ & SESA2-2 & SESA20-2 & PawS1 & PawS2 & SESA3* \\
\hline Ala & 3 & 3 & 3 & 3 & 3 & 4 & 3 \\
Arg & 9 & 9 & 16 & 15 & 2 & 1 & 7 \\
Asn & 4 & 4 & 6 & 5 & 4 & 5 & 6 \\
Asp & 1 & 1 & 4 & 3 & 1 & 1 & 3 \\
Cys & 8 & 8 & 8 & 8 & 8 & 8 & 8 \\
Gln & 41 & 41 & 31 & 30 & 26 & 23 & 8 \\
Glu & 6 & 6 & 10 & 10 & 4 & 4 & 10 \\
Gly & 5 & 5 & 5 & 6 & 4 & 4 & 5 \\
His & 1 & 1 & 1 & 1 & 3 & 4 & 3 \\
Ile & 4 & 4 & 7 & 7 & 4 & 4 & 3 \\
Leu & 9 & 9 & 4 & 4 & 8 & 8 & 9 \\
Lys & 3 & 3 & 0 & 1 & 7 & 8 & 4 \\
Met & 1 & 1 & 4 & 4 & 3 & 3 & 16 \\
Phe & 3 & 3 & 3 & 3 & 1 & 1 & 0 \\
Pro & 3 & 3 & 10 & 10 & 3 & 4 & 6 \\
Ser & 6 & 6 & 4 & 4 & 3 & 2 & 5 \\
Thr & 3 & 4 & 1 & 2 & 1 & 0 & 1 \\
Trp & 0 & 0 & 0 & 0 & 0 & 0 & 1 \\
Tyr & 0 & 0 & 3 & 3 & 1 & 1 & 3 \\
Val & 6 & 6 & 8 & 8 & 5 & 5 & 2 \\
Total & 116 & 117 & 128 & 127 & 91 & 90 & 103 \\
\hline *) According to Kortt $e$ al (1990) the amino acid & composition of SESA3 and the two isoforms SESA3-a are identical
\end{tabular}

(*) According to Kortt et al. (1990) the amino acid composition of SESA3 and the two isoforms SESA3-a are identical. 


\section{Figure Legends}

Figure 1: Analytical RP-HPLC profile of crude albumins after size exclusion purification. After FPLC separation the albumin-rich fraction was further purified by RP-HPLC. The SESA2-1, SESA2-2 and SESA20-2 fractions were further reduced and alkylated and LC-MS data were acquired. The $~ 95 \%$ pure SESA3 analogues SESA3-a, SESA3-b and SESA3-c were digested with trypsin, analyzed by MS/MS and the resulting spectra searched against public and custom-built protein databases.

Figure 2: 1D gel electrophoresis of purified sunflower albumins reveals their existence as monomers. 1D gel electrophoresis of non-reduced and reduced sunflower albumins confirmed that (A) SESA2-1, SESA2-2 and (B) SESA20-2, SESA3, SESA3-a all exist as single chain albumins and are not cleaved into small and large subunits like the sunflower albumins PawS1 and PawS2.

Figure 3: Experimental isotopic peak envelops showing average and monoisotopic masses of the two isoforms of the first albumin of SESA2 (SESA2-1). (A) Preproalbumin sequence of SESA2 (grey) with the confirmed albumin sequence highlighted in bold black and underlined. The additional threonine at the C-terminal position of the second isoform of SESA2-1 is highlighted by a broken underline. (B, E) Experimental isotopic peak envelops showing average and monoisotopic masses of SESA2-1 isoforms I and II, respectively. (C, F) Protein mass reconstructions of native SESA2-1 isoforms I and II, respectively (D, G) Protein mass reconstructions of reduced and alkylated (iodoacetamide) SESA2-1 isoforms I and II, respectively, confirming that SESA2-1 remains as a single chain protein and is not cleaved into a small and a large subunit.

Figure 4: Experimental isotopic peak envelop showing average and monoisotopic masses of the second albumin of SESA2 (SESA2-2). (A) Preproalbumin sequence of SESA2 (grey) with the confirmed albumin sequence highlighted in bold black and underlined. (B) Experimental isotopic peak envelop showing average and monoisotopic masses of SESA2-2. (C) Protein mass reconstruction of native SESA2-2. (D) Protein mass reconstructions of reduced and alkylated (iodoacetamide) SESA2-2, confirming that SESA2-2 remains as a single chain protein and is not cleaved into a small and a large subunit.

Figure 5: Experimental and theoretical isotopic peak envelops showing average and monoisotopic masses of the second albumin of SESA20 (SESA20-2). (A) Preproalbumin sequence of SESA20 (grey) with the confirmed albumin sequence highlighted in bold black and underlined. (B) Experimental isotopic peak envelop showing average and monoisotopic masses of SESA20-2. (C) Protein mass reconstruction of native SESA20-2. (D) Protein mass reconstructions of reduced and alkylated (iodoacetamide) SESA20-2, confirming that SESA20-2 remains as a single chain protein and is not cleaved into a small and a large subunit.

Figure 6: Analytical RP-HPLC separation profile and experimental isotopic peak envelope showing average and monoisotopic masses of the SESA3 analogues SESA3-a, SESA3-b and SESA3-c. (A) Analytical RP-HPLC profile demonstrating the purity of the sunflower albumin SESA3-a fraction. (B) Experimental isotopic peak envelope showing average and monoisotopic masses of two isoforms I and II of the albumin SESA3-a. Methylation at Asn9 appears to be the cause of the mass difference of 14 Da between the two isoforms. (D) Analytical RP-HPLC profile demonstrating the purity of the sunflower albumin SESA3-b fraction. (C) Experimental isotopic peak envelope showing average and monoisotopic masses of two isoforms I and II of the albumin SESA3-b. (F) Analytical RP-HPLC profile demonstrating the purity of the sunflower albumin SESA3-c fraction. (E) Experimental isotopic peak envelope showing average and monoisotopic masses of the albumin SESA3-c.

Figure 7: MS/MS data obtained from a 5600 TripleTOF $^{\mathrm{TM}}$ mass spectrometer showing methylation of Asn9, which results in a mass difference of 14 Da between isoforms I and II of the sunflower albumin SESA3-a. (A) MS/MS spectrum showing no modification of isoform I. (B) MS/MS spectrum showing methylation of b9-ion at Asn9 of isoform II.

Figure 8: Preproalbumins from Helianthus annuus. Selected sunflower preproalbumins showing conserved cysteine connectivity (I-V, II-III, IV-VII and VI-VIII) and differences in precursor structure. PawS1 not only encodes a heterodimeric albumin but also a small cyclic peptide called SFTI-1. SESA3 encodes one single monomeric albumin. SESA2 is a double precursor and give rise to two mature monomeric albumins. SESA20 is also a double precursor and gives rise to two mature albumins. SESA20-2 remains in the monomeric form. According to Jayasena et al. (2016 [20] SESA20-1 exists at the protein level, but the structural form (monomeric or heteromeric) could not be confirmed here due to its low abundance. The number in square brackets (e.g. SESA2[158-285]) refers to the corresponding sequence of the mature albumin form. 


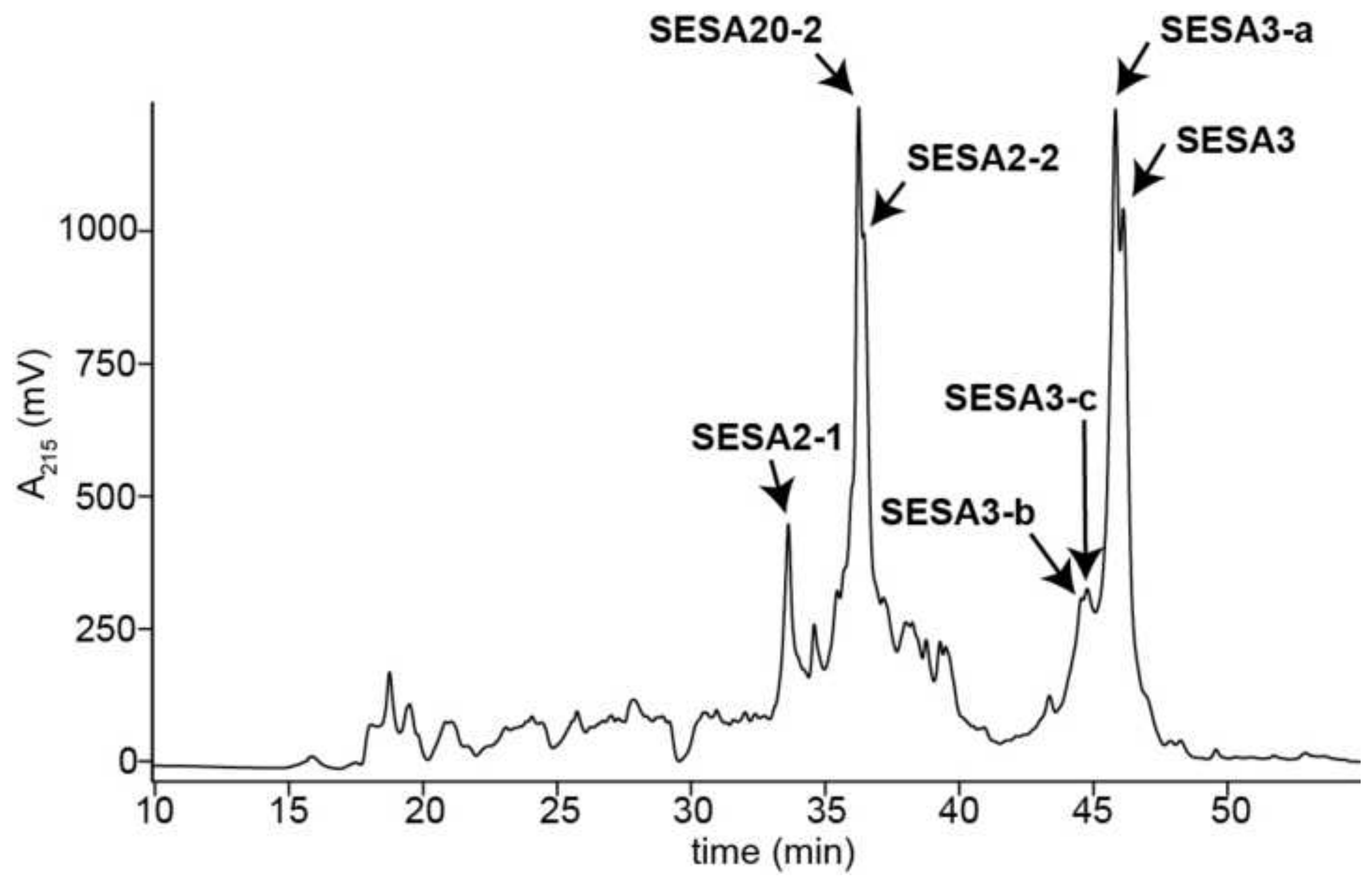


A

$\mathrm{kDa}$

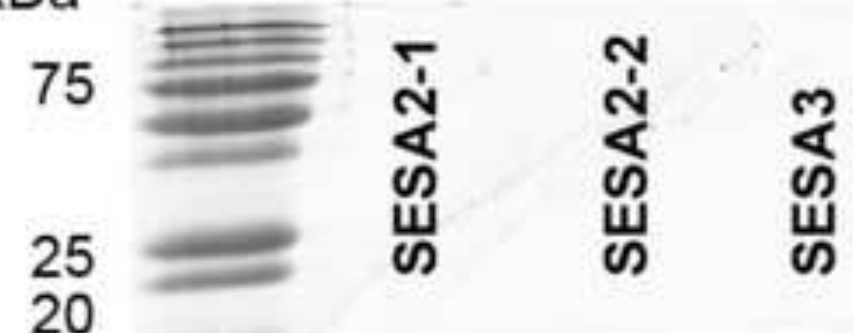

20

15

10

5

2

non-reduced

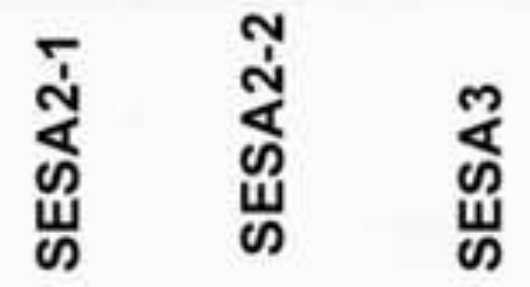

reduced

B

$\mathrm{kDa}$

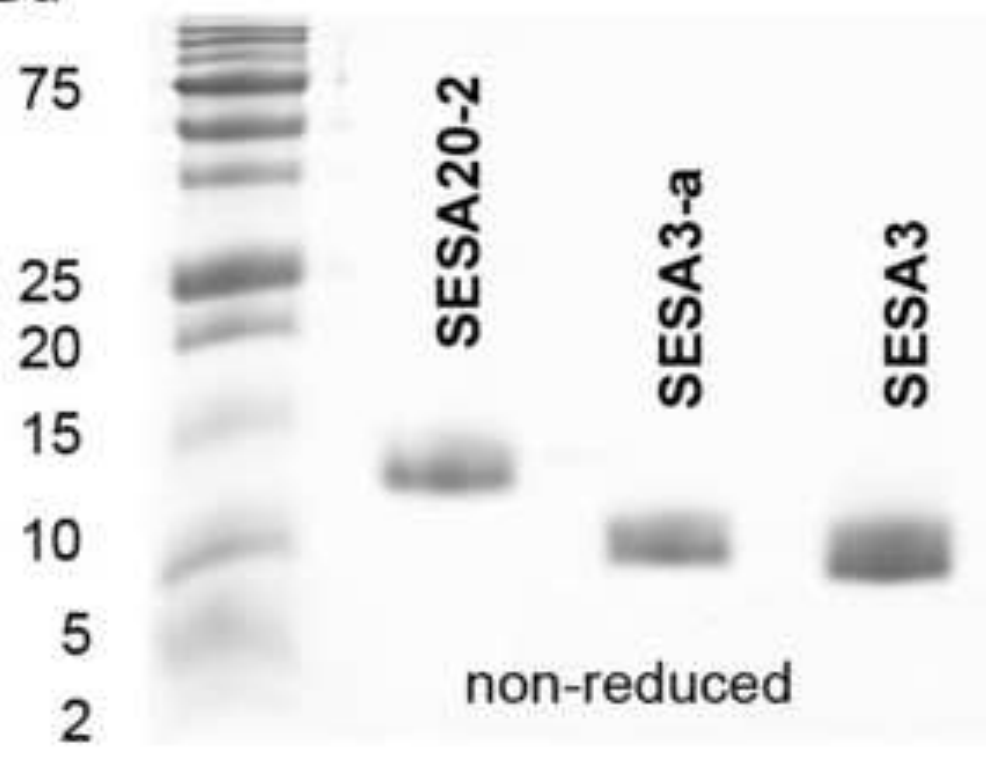

reduced 
A MATKTLLFLALAALVAFATAHTTI ITTTIEDENPLSEQRQCSQQVQGQRLNQCRMFLQQGQRGQQHQQQQEQ QLLQQCCQELQNIDQQCQCEAVKQVFREAQQQVQQQQGRQSVPFRSSQQTQQLKQKAQILPNVCNLQSRRCE IGTITTTVVTESN ID IP FRDRPFGR $Q Q C S E T E I Q R P V S Q C Q R Y V E Q M Q S P M P Y I R R P G Q Q Q Q E P E L Q Q C C$ NQLQNVNRECQCEAVQEVARRVMRQPQQHQQQQRRRGQFGGQEMDIARRVIQNLPNQCDLEVQQCNI PY
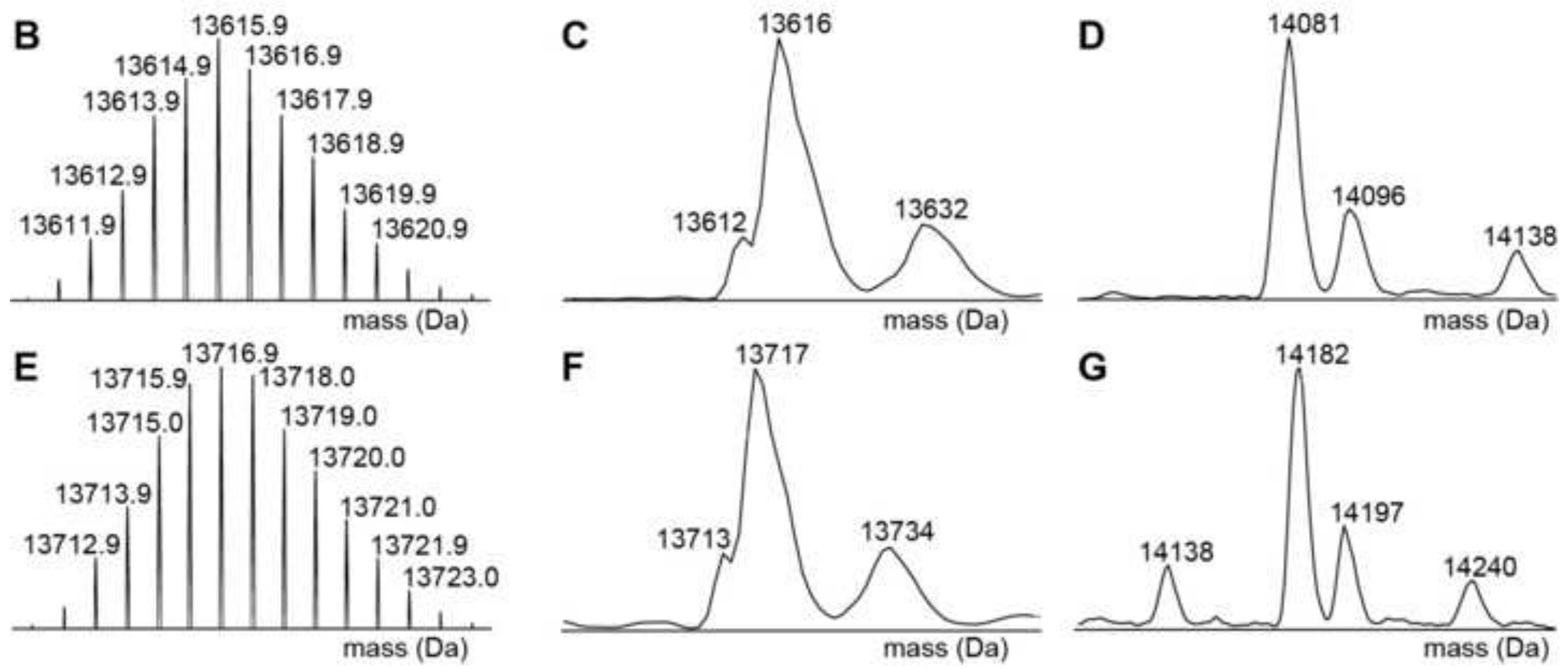
A MATKTLLFLALAALVAFATAHTTIITTTIEDENPLSEQRQCSQQVQGQRLNQCRMFLQQGQRGQQHQQQQEQ QLLQQCCQELQNIDQQCQCEAVKQVFREAQQQVQQQQGRQSVPFRSSQQTQQLKQKAQILPNVCNLQSRRCE I GTITTTVVTESN IDIPFRDRPFGRSQQCSETEIQRPVSQCQRYVEQQMQSPMPYIRRPGQQQQEPELQQCC NQLQNVNRECQCEAVQEVARRVMRQPQQHQQQQRRRGQFGGQEMDIARRVIQNLPNQCDLEVQQCNIPY
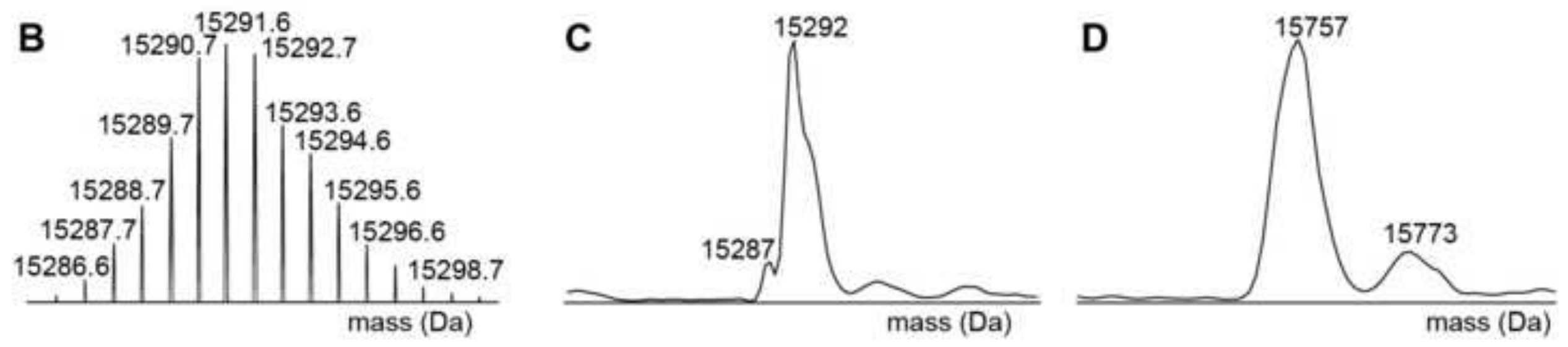
A MAKLIVLALAFAALVAFATAHTTI ITTTIEDENPISGQRQCSQRIQGQRLNQCRMFLQQGQNIPREFDNPQM GRQQQEQQLLLQCCQELQNIDQQCQCEAVKQVFREAQQQVQQQQGPQSVPFLHSQQAQRLKQKAQILPNVCN LQSRRCE I GT ITTIVTE SN IDIPERDRPFGTGSQQCRETE IQRPVSQCQRYVEQQMQSPMPYIRRPGQQQQEP ELQQCCNELQNVKRECQCEAVQEVARRVMRQPQQHQQQRRGQFGGQEMDIARRVIQNLPNQCSLQVQQCNIPY

B

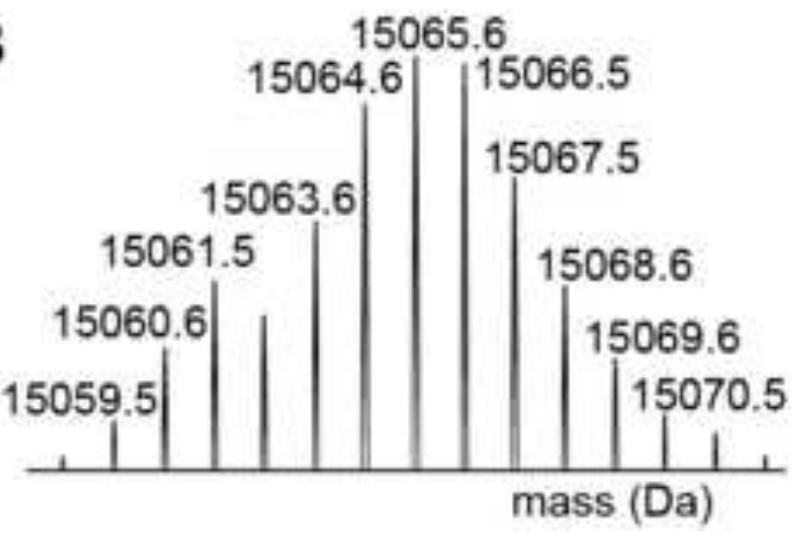

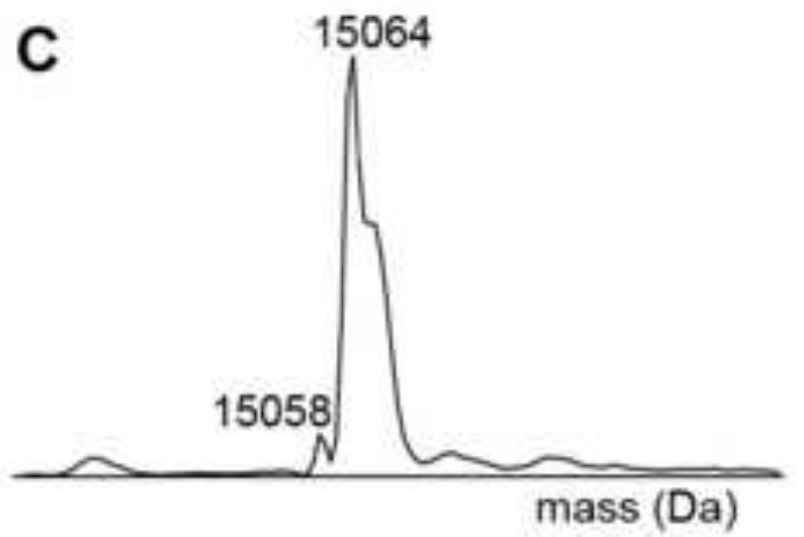

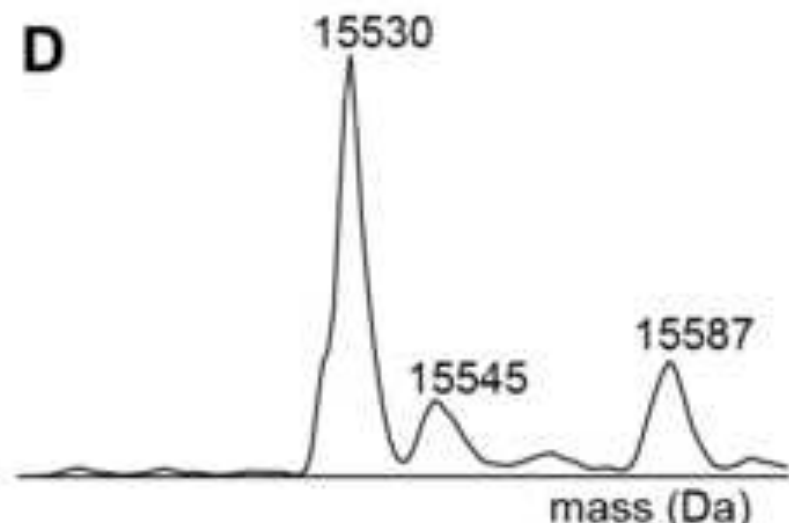


A
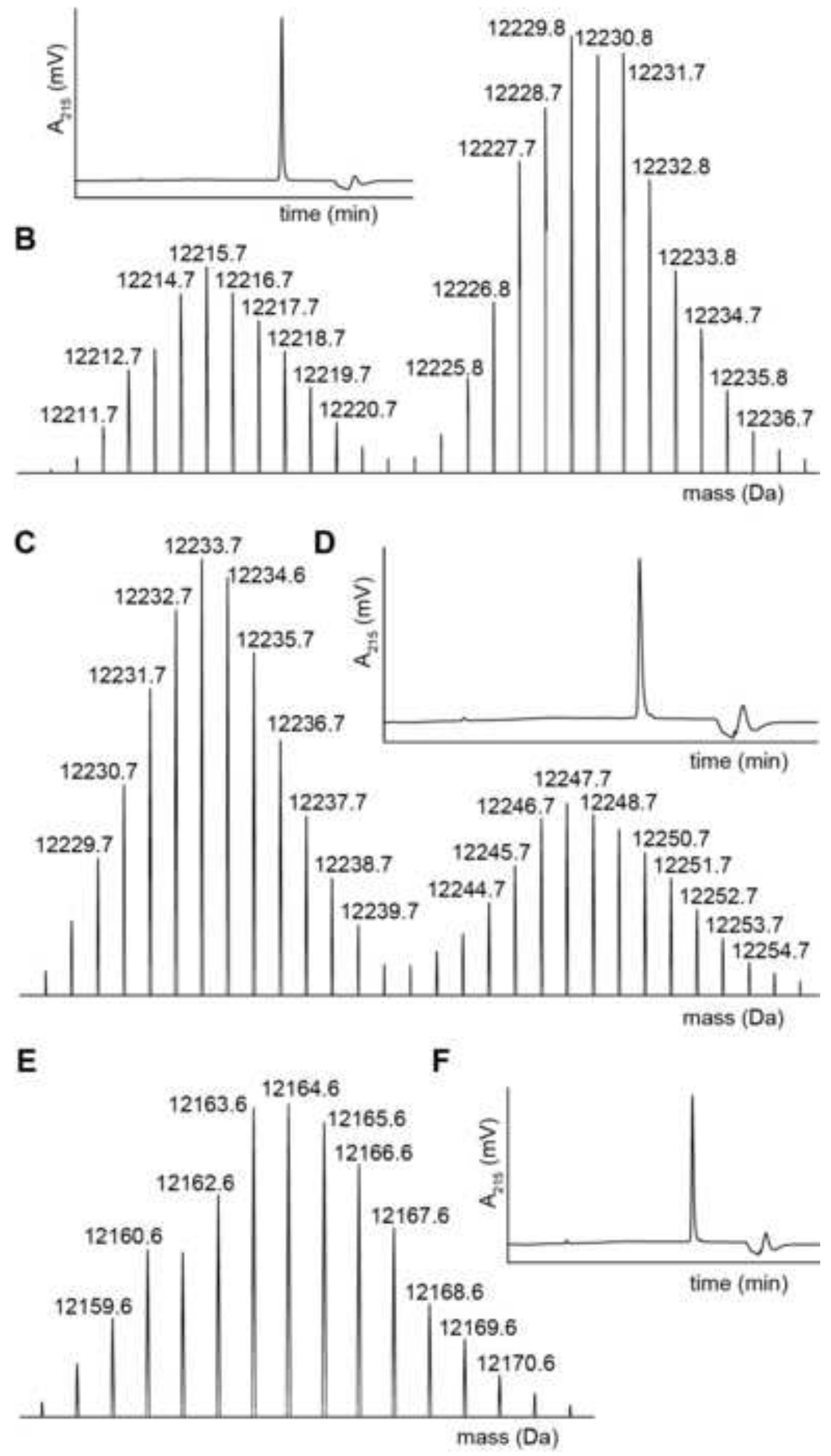


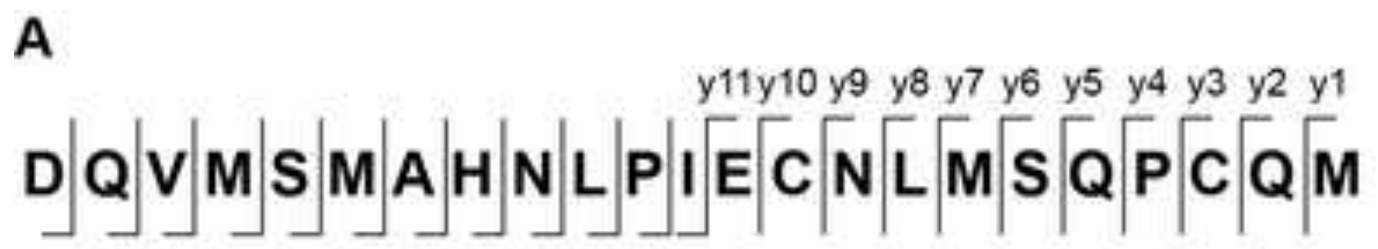

b1 b2 b3 b4 b5 b6 b7 b8 b9b10b11b12

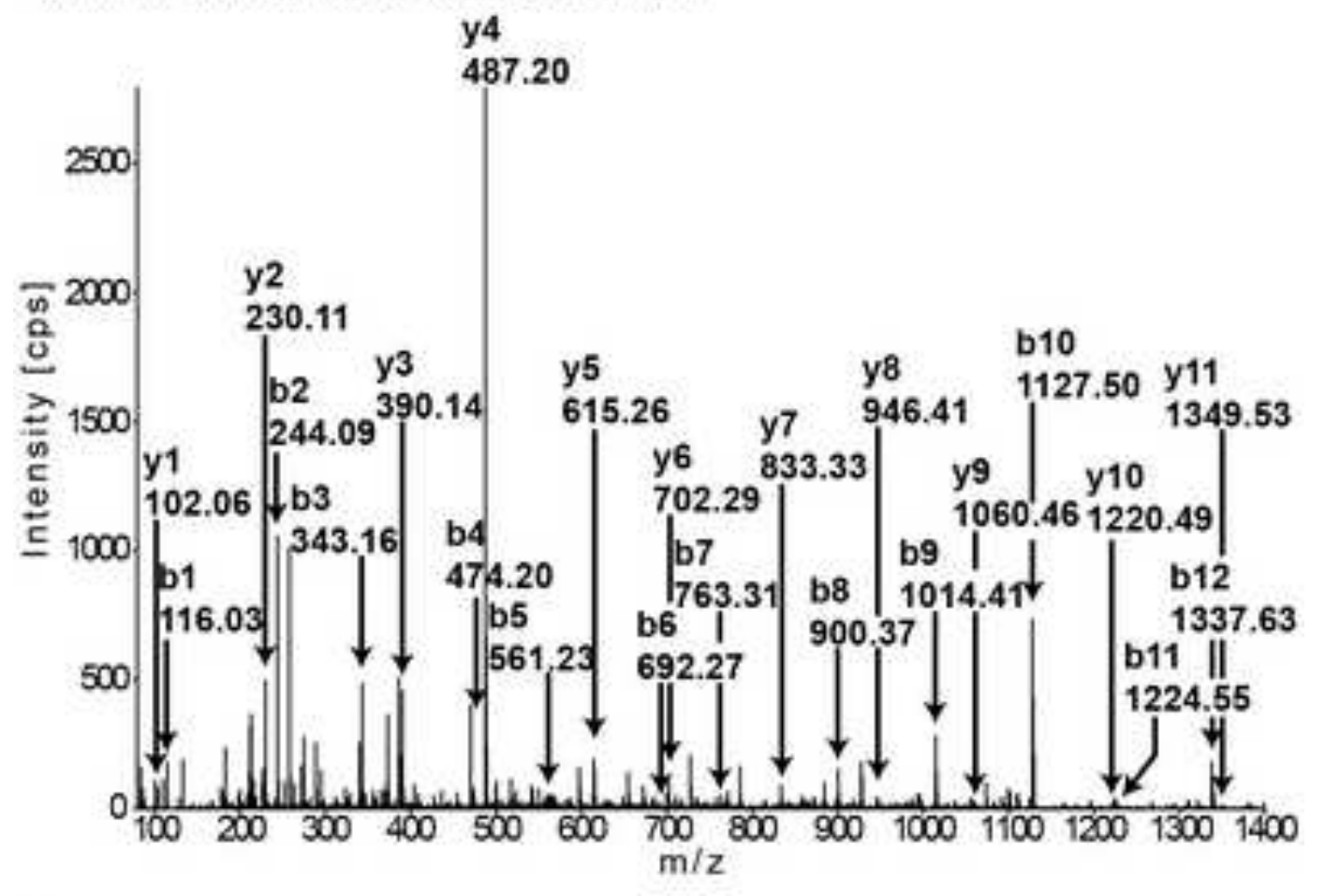

B

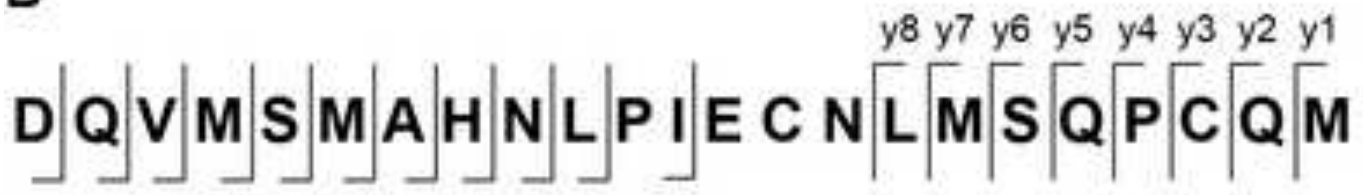

b1 b2 b3 b4 b5 b6 b7 b8 b9 b10 b11

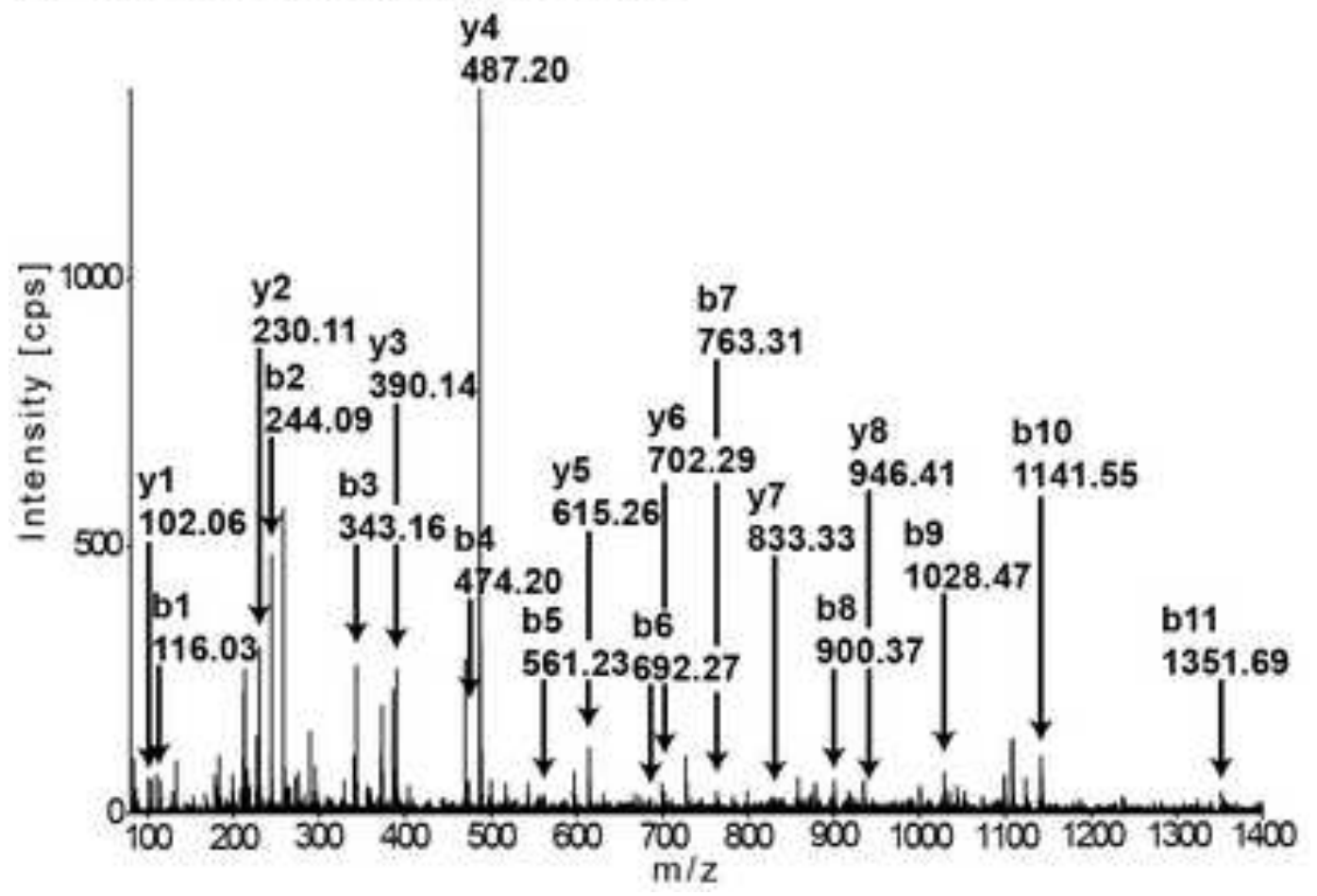




\section{PawS1}

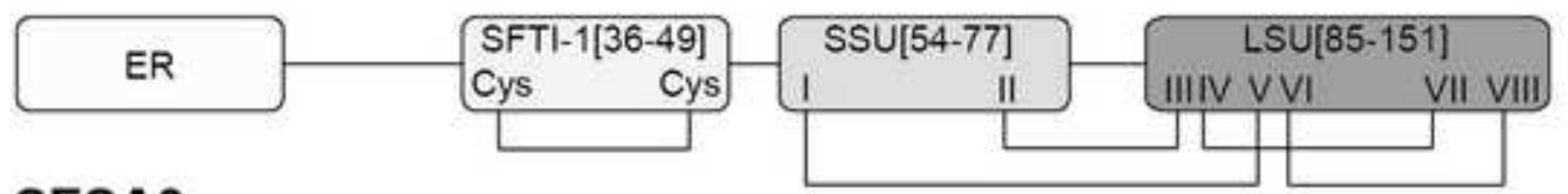

\section{SESA3}

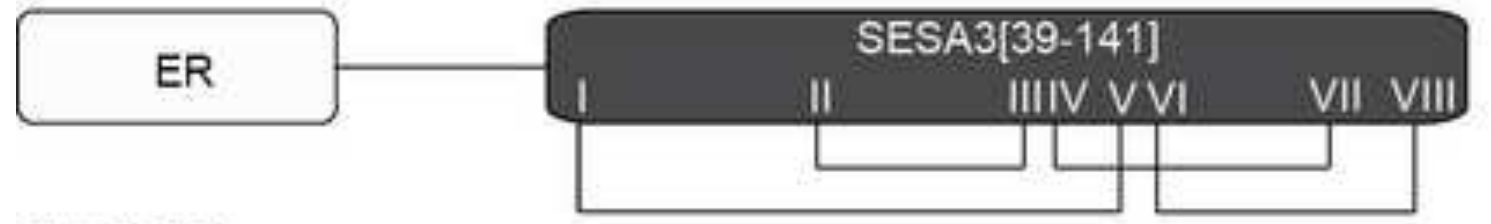

\section{SESA2}

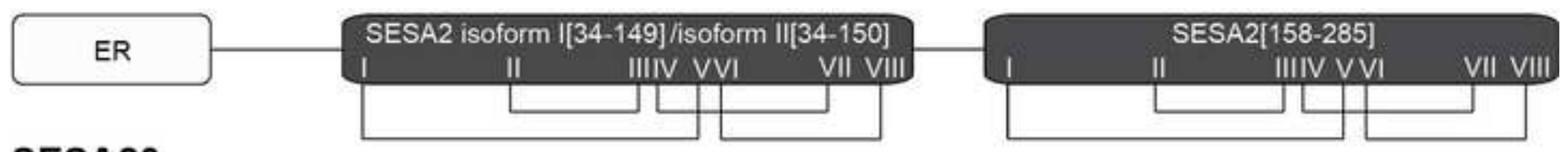

SESA20
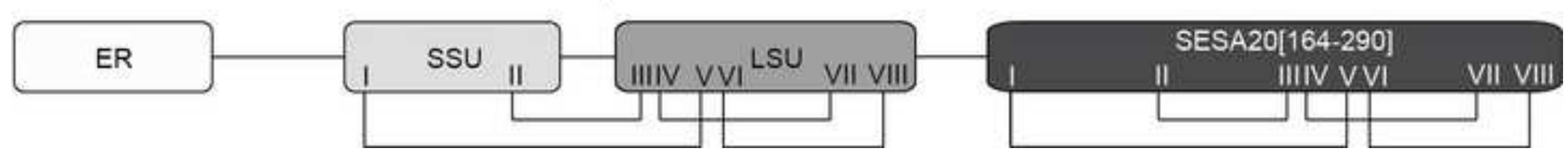


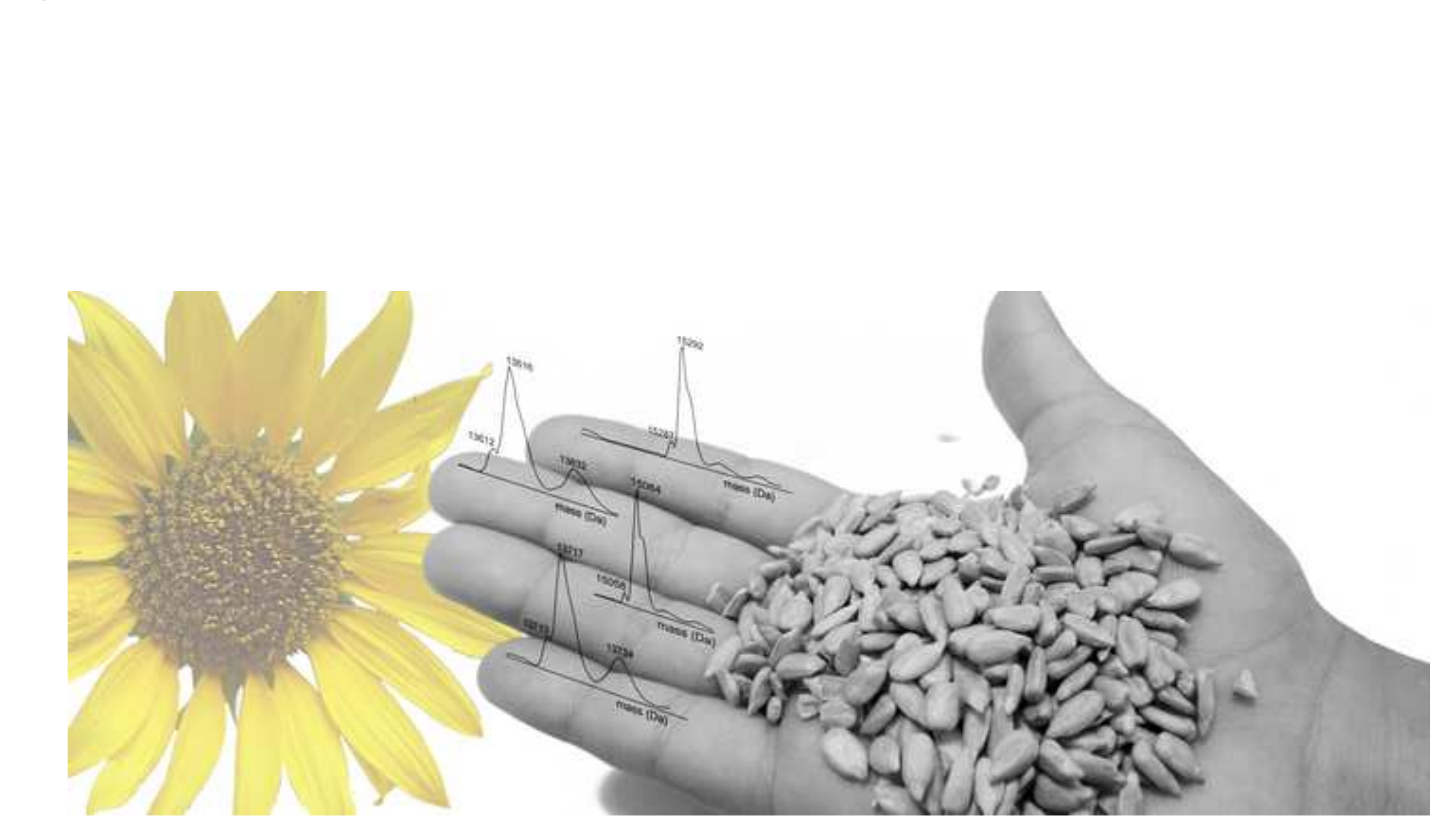

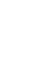
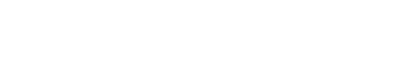